\title{
NEOINSTITUCIONALISMO E A ANÁLISE DE POLÍTICAS PÚBLICAS: ESTABILIDADE E RUPTURA INSTITUCIONAL
}

Alexandre José Romagnoli ${ }^{1}$

\begin{abstract}
Resumo
Este trabalho consiste em um estudo que pertence a uma pesquisa maior de doutorado, ainda em curso, que busca articular o neoinstitucionalismo (novo institucionalismo) a um modelo de análise de políticas públicas, mais especificamente, de formação de agenda de governo - Agenda-setting, chamado Teoria do Equilíbrio Pontuado (Punctuated Equilibrium Theory - PET), dos autores Frank Baumgartner e Brian Jones (1993). A relação estudada se estabelece a partir do debate acerca das mudanças institucionais, dado que há um enfoque nos trabalhos voltados apenas para a estabilidade proporcionada pelos arranjos institucionais. A partir de levantamento bibliográfico acerca do neoinstitucionalismo comparativo ao modelo de análise em questão, foi possível depreender a importância do neoinstitucionalismo para a compreensão do processo político, que associado a modelos recentes de análise de políticas públicas - neste caso, o PET, permitem avançar no debate propondo novo instrumental de estudo neste campo da Ciência Política brasileira, dado que aplicações deste modelo se concentram na realidade norte-americana.
\end{abstract}

Palavras-Chave: Neoinstitucionalismo; estabilidade; ruptura; políticas públicas.

\section{INTRODUÇÃO}

Este trabalho consiste em um estudo parte de uma pesquisa de doutorado que vem sendo desenvolvida no Programa de Pós-Graduação em Ciências Sociais da Unesp, na Faculdade de Ciências e Letras de Arararaquara - SP. Tem como objetivo principal analisar o neoinstitucionalismo associado a novos modelos de análise de políticas públicas enfocando a questão da estabilidade e ruptura institucional. Dentre estes recentes modelos, escolhemos o Modelo do Equilíbrio Pontuado (Ponctuated Equilibrium Model), proposto por Frank R. Baumgartner e Bryan D. Jones (1993) exatamente pelo enfoque dado à análise do processo político a partir da dinâmica de estabilidade e mudanças nas políticas públicas, consequentemente, na arquitetura institucional envolvida.

Inicialmente, é apresentada uma reconstrução histórica sobre o institucionalismo com o objetivo de melhor delimitar a construção teórica do que se convencionou chamar posteriormente de

\footnotetext{
${ }^{1}$ Universidade Estadual “Júlio de Mesquita Filho" - UNESP/FCLAr, alexandre.romagnoli@ifsp.edu.br e ORCID 00000002-7600-3473.
} 
o novo institucionalismo - ou neoinstitucionalismo. Em seguida, munidos desse arcabouço teórico, passa-se para a discussão da importância das instituições dentro do contexto de estabilidade e mudanças no cenário político social. Em outras palavras, a questão que se coloca é que se os arranjos institucionais condicionam o comportamento dos indivíduos, produzindo estabilidade, como encarar a mudança? Como interpretá-la, entendê-la? Percebe-se que na literatura há uma acentuada concentração de estudos voltados para a estabilidade e uma escassez de trabalhos que abordem as mudanças institucionais.

Associada a essa questão, possuímos atualmente modelos, ainda pouco explorados no contexto brasileiro, de análise de políticas públicas que dialogam diretamente com a literatura neoinstitucional, bem como a compreensão de processos de estabilidade e mudança. $\mathrm{O}$ modelo apresentado e estudado é a Teoria do Equilíbrio Pontuado de Baumgartner e Jones (1993).

Em síntese, este artigo busca revisitar autores relevantes acerca do neoinstitucionalismo na Ciência Política com o propósito de aprofundar a compreensão do modelo de análise de políticas públicas proposto, seus avanços e limitações, contribuindo para o desenvolvimento de um estudo maior, já citado, de uma pesquisa de doutorado.

\section{O INSTITUCIONALISMO COMO BASE TEÓRICA DE ANÁliSE NA CIÊNCIA POLÍTICA}

Há tempos o debate acerca da centralidade das instituições na explicação do processo político é latente na Ciência Política. O amplo debate, que parcialmente será abordado nessa seção, pode ser sintetizado a partir dos seguintes questionamentos presentes, direta ou indiretamente, nas várias obras que buscaram investigar e aprofundar o tema: as decisões políticas são resultado direto de indivíduos que agem de forma isolada e egoísta, ou, por outro lado, são processos induzidos por instituições políticas e sociais que regulam as escolhas coletivas? (PERES, 2008).

A busca pela resposta a essas questões, amparada por outras significativas áreas das ciências humanas, originou um grande arcabouço teórico que representou a retomada do viés institucional como premissa analítica, culminando no que, posteriormente, denominamos de neoinstitucionalismo. Para a devida compreensão desse processo de construção teórica, faz-se necessário o conhecimento de sua evolução histórica.

No entanto, antes de avançarmos nas considerações contextuais históricas e teóricas do tema, é essencial apresentarmos uma definição do que se entende por instituições. Dos vários autores que 
abordam o assunto, este trabalho escolhe a definição oferecida por Douglas North, dada a sua grande aceitação entre os pensadores da área. Segundo o autor, as instituições são regras, constrangimentos formais e/ou informais e as características de afirmação e garantia de ambos. Em outras palavras, as regras do jogo, pois, se as instituições são as regras, as organizações são os jogadores (NORTH, 1993)

Dado o conceito de instituições que baseará este estudo, retomemos o processo histórico com foco na compreensão do neoinstitucionalismo. Paulo Sérgio Peres (2008) afirma em seu trabalho que a devida compreensão do neoinstitucionalismo, ou seja, a retomada das instituições como objeto central de investigação política, passa, necessariamente, pelo embate de vários pesquisadores pertencentes a ciências sociais em relação às premissas comportamentalistas. Ou seja, é fruto da contraposição entre institucionalismo e comportamentalismo.

O estudo sobre o papel e importância das instituições na compreensão do processo político possui longa tradição. O antigo institucionalismo (em contraste ao neoinstitucionalismo surgido posteriormente) tem suas bases em consideráveis trabalhos que vão desde Aristóteles, com os estudos sobre as constituições atenienses, passando pelo contratualista Locke, por Tocqueville, com os estudos sobre a democracia dos Estados Unidos, até Émile Durkheim com a sociologia emergente.

No entanto, foi em 1961, que Redford, presidente da American Political Science Association (APSA), anuncia grandes mudanças quanto ao estudo do fenômeno político, até então centrado em análises especulativas e excessivamente formais. Isso porque, essas abordagens passaram a não mais dar conta de explicar fatos políticos originários da década de 1930, como o nazismo, o fascismo, apatia política, etc. A partir de então, os estudos passaram a se pautar em uma maior sofisticação metodológica, que contasse com hipóteses testáveis, generalizáveis, voltados para a investigação factual. A esse momento, chamamos de "revolução comportamentalista" (DAHL, 1963; HALL e TAYLOR, 2003).

De forma geral, Peres (2008), destaca dois pontos fundamentais para compreender a entrada do comportamentalismo - designação genérica do behaviorismo - na Ciência Política: a) a crítica enfática à abordagem institucional, propondo uma teoria empiricamente orientada; e b) uma proposta de associar métodos de pesquisa de outras ciências das humanidades como sociologia, antropologia e psicologia.

O modelo comportamentalista atinge seu auge durante os anos de 1950 até meados de 1960. Então, novamente, após discurso presidencial da APSA há o registro de sua crise enquanto modelo teórico. Dentre os motivos encontrados sobre sua falência analítica estão a dificuldade empírica de 
análise e o seu ecletismo multidisciplinar, visto nesse momento como uma perda de foco da ciência política. (MARQUES, 1997).

É a partir de então que as instituições são retomadas no debate teórico vigente, agora, em um modelo teórico "reestruturado" que passa a levar em conta a dupla rejeição que ensejou as mudanças anteriormente: 1. a falta de cientificismo do antigo institucionalismo, "sucumbido" pelo comportamentalismo; 2. a reincorporação das instituições ausentes nas abordagens comportamentalistas. Em suma, temos o neoinstitucionalismo representando o ressurgimento do paradigma institucional com a manutenção da proposta de instituições no centro da análise e aderindo à incorporação das preocupações que caracterizaram o comportamentalismo com relação ao rigor científico.

Como não se trata de uma corrente de pensamento unitária - como já citado nas afirmações anteriores - o neoinstitucionalismo reúne diferentes escolas, o que se convencionou chamar de: neoinstitucionalismo histórico, neoinstitucionalismo da escolha racional e neoinstitucionalismo sociológico (HALL; TAYLOR, 2003).

O neoinstitucionalismo da escolha racional, originário da teoria da escolha racional, baseia-se na ideia de que as motivações e preferências dos indivíduos se dão a partir de um mecanismo racional de tomada de decisão quando estão diante de alternativas excludentes. Estamos tratando do individualismo metodológico da matriz econômica neoclássica, em que o seu modelo tem como fundamento a maximização de utilidades. Aqui as instituições são fundamentais para a definição das estratégias dos indivíduos, pois condicionam os comportamentos e preferências dos atores (MARQUES, 1997).

Já o neoinstitucionalismo sociológico apresenta uma definição mais abrangente do conceito de instituição. Não se baseia apenas em conjuntos de regras e procedimentos formais, mas também em dimensões sociais e culturais, ou seja, os costumes, modelos morais, simbólicos também são considerados importantes no processo de constrangimento da ação estratégica do indivíduo. Não se trata apenas de um cálculo racional, mas também da busca da própria legitimidade frente aos seus membros (HALL; TAYLOR, 2003).

Por fim, o neoinstitucionalismo histórico possui a preocupação de construir análises pautadas no contexto político, social e histórico. Esta abordagem vai além da concepção presente na teoria da escolha racional, onde as instituições dão forma às estratégias dos indivíduos, mas também condicionam suas preferências e metas. Para os autores neoclássicos e neoinstitucionalistas da escolha racional as preferências são exógenas ao modelo, já para os neoinstitucionalistas históricos 
as preferências são endógenas, sendo construídas social e politicamente no bojo dos processos sob estudo" (MARQUES, 1997).

Munidos das informações referentes ao neoinstituicionalismo, seu processo de delimitação teórica e organizações próprias da sua aplicação na Ciência Política, passemos para a segunda sessão desse trabalho, voltada para a questão da continuidade associada às instituições em contraponto às suas mudanças e rupturas, mais raras, porém igualmente importantes de serem analisadas. Esse caminho de estudo é importante para garantir a compreensão e melhor profundidade de apreciação do modelo de análise de políticas públicas proposto posteriormente.

\subsection{ESTABILIDADE E RUPTURA INSTITUCIONAL NO CONTEXTO DEMOCRÁTICO}

Dado que os arranjos institucionais, nos quais os indivíduos estão inseridos, constrangem o comportamento estratégico destes, e que as instituições também funcionam como aparatos de redução de incertezas, é indutivo pensar que existe estabilidade social originária dessa construção. As instituições não são modificadas facilmente, através de quaisquer forças que atuem direta ou indiretamente sobre elas. Disso resulta o debate acerca da estabilidade e ruptura/mudança institucional.

Rothestein (1998) argumenta sobre esse debate utilizando, inicialmente, argumento de base econômica ao afirmar que não há interesse na mudança institucional devido aos custos relativos a este processo, bem como a incerteza criada no longo prazo. Partindo de outras abordagens, agora cultural, histórica, a argumentação também indica a perpetuação institucional ao longo do tempo. Afirma que no decorrer do tempo, diferentes atores, com diferentes argumentos e interesses garantiram o funcionamento de instituições a partir de outras previamente existentes, criando uma dependência de trajetória (path dependence).

Diante desta informação, em que as diferentes abordagens institucionalistas apontam para a ideia de que os arranjos institucionais geram estabilidade, como encarar a mudança? Se a dinâmica criada pelo próprio sistema conduz à sua perpetuação, como explicar o processo de ruptura e alteração institucional?

Uma possível explicação pautada em uma abordagem econômica funcionalista afirma que a mudança advém de novas demandas de necessidade dos atores e seus grupos. No mesmo sentido, afirma-se que a mudança acontece através de agentes que de dentro das organizações percebem 
oportunidades presentes no ambiente externo ou a aquisição de novos conhecimentos capazes de impulsionar a mudança (ROTHSTEIN, 1998; NORTH, 1993).

Associado a este processo de mudança surge a figura do "empreendedor político" que desponta como importante ator nos momentos de mudanças abruptas e inesperadas. De uma maneira geral, estudos mais recentes internacionais destacam a importância do empreendedor político também denominado empreendedor institucional em algumas obras, apontando a relevância do papel dos atores, representando o poder e os interesses no processo de compreensão da alteração das instituições (DIMAGGIO, 1988). A literatura afirma que estes são capazes de articular as informações e interesses em torno do problema percebido proporcionando o caminho para o nascimento de outras organizações com outros interesses. As grandes mudanças, pontuais e significativas, surgem, então, como resultado da ausência de instituições capazes de mediar o processo conflitivo presente, o que significa dizer a incapacidade de acomodação e formação de compromissos entre as partes interessadas (NORTH, 1993).

Levi (1991), em seu trabalho, também se dedica a analisar o processo de mudança das instituições. Afirma que "a durabilidade das instituições faz com que elas passem a ser algo de difícil alteração; ao mesmo tempo, faz com que as grandes transformações, quando ocorrem, sejam tão interessantes de se estudar" (p. 81). Para a autora, instituições formais são como regras socialmente construídas que refletem uma distribuição de recursos de poder. Logo, as instituições se tornam suscetíveis à mudança a medida em que esta distribuição se altera. Complementa que a mudança é resultado de um aumento de eficiência de indivíduos que querem a mudança, ao posso que diminui o poder de bloqueio, veto, daqueles cujos interesses estão garantidos pelo arranjo corrente.

Em seu estudo, a autora propõe o que chama de "consenso contingente" ou fairness, que implica na ideia de reciprocidade de comportamentos com relação a expectativas alheias. Faço porque os outros também fazem; coopero. As "instituições representam uma barganha social a partir da qual emergem retornos de obediência” (p.84). Em outras palavras, as instituições são estáveis quando são capazes de acomodar grupos e pessoas gerando obediência. Há, necessariamente, que existir a percepção de ganho entre as partes para justificar a instituição. Se os atores envolvidos não receberem, minimamente, sua parte da baganha, torna-se excessivamente custosa a implementação institucional e esta enfraquece, abrindo espaço para o processo de mudança.

Por fim, a autora sintetiza seu argumento a partir de três pontos que mantém a estabilidade institucional: 1 . quando os benefícios oferecidos forem significativos; 2. quando o custo da mudança 
for muito alto; 3. pela falta de capacidade dos insatisfeitos de conceber alternativas à situação vigente (LEVI, 1991).

Produções acadêmicas mais atuais acerca do processo de mudanças das instituições permanecem inseridas nessa ótica que busca compreender as rupturas através da relação entre instituições/ regras/ local e os atores envolvidos no processo. Mahony e Thelen (2010) apresentam um modelo para explicar diferentes formas de alteração institucional afirmando que se deve considerar as características do contexto político, as características da instituição e, por fim, o tipo dominante de agente de mudança que surgirá a partir dessa relação.

Os autores apresentam a teoria da mudança gradual. Para tanto, criticam o enfoque demasiado nos processos abruptos de mudança, geralmente construídos a partir de consequências de fatores exógenos às instituições. Propõem, então, o desenvolvimento de estudos baseados em fatores endógenos que frequentemente conduzem a mudanças incrementais. A mudança institucional gradual pode ser do tipo: a) displacement; b) layering; c) drift; e) conversion ${ }^{2}$. A compreensão desses tipos de mudança institucional, levando em conta o papel que os atores desempenham, conduz para análises do como e do porque cada um dos tipos de mudanças ocorrem.

Mahony e Thelen (2010) também apresentam uma classificação dos atores/agentes a partir das diferentes estratégias empregadas diante de diferentes ambientes institucionais: i) insurrectionaries, ii) symbionts, iii) subversives e iv) opportunists. De uma maneira geral, os autores apresentam as especificidades de cada um desses atores a partir de seus comportamentos diante das seguintes perguntas: “o ator busca preservar as regras institucionais existentes?" e "o ator cumpre as regras institucionais?”. (GOMES, 2013).

A discussão acerca da estabilidade e mudança institucional também perpassa o debate sobre a democracia. Autores como Przeworski, Cheibub e Limongi (2003) afirmam através de uma perspectiva institucionalista que comportamentos cívicos são gerados a partir de arranjos institucionais democráticos, o que garante maior estabilidade e garantia ao regime no tempo. No mesmo sentido, Rocha (2009) afirma que "a chave do sucesso de ações públicas eficientes dependeria da existência de uma burocracia pública autônoma, coesa, coerente, disciplinada, tecnicamente preparada e com espirit de corps" (p. 868).

Dentro do mesmo debate, instituições e democracia, Moisés (2005) também argumenta sobre a importância das instituições dentro do processo de garantia da democracia no decorrer do tempo.

\footnotetext{
${ }^{2}$ Mais informações acerca dos tipos de mudança institucional gradual, bem como da classificação dos agentes condutores das mudanças, ambos propostos por Mahoney e Thelen (2010), consultar a aplicação realizada através do trabalho de Gomes (2013).
} 
Constrói seu argumento relembrando, inicialmente, o período a partir de 1930 onde, desde então, o país passou a vivenciar várias mudanças políticas - pelo menos três - que representaram enfraquecimentos do regime democrático por regimes autoritários, o que indicaria bases institucionais pouco sólidas no país, logo, pouca estabilidade.

Prossegue, no entanto, indicando que o país passa a vivenciar um novo período, mais virtuoso, desde de 1985. Afirma que as instituições democráticas têm funcionado com relativa harmonia e, principalmente, com continuidade no tempo, seguindo certo padrão incremental de desenvolvimento. A estabilidade se deu mesmo diante de fatos como impeachment e sérias denúncias de corrupção. Desde então as sucessões presidenciais ocorrem de acordo com as regras definidas dentro de um quadro de cooperação e harmonia (MOISES, 2005). Em suma, seu argumento enfoca tanto a estabilidade democrática possível a partir das instituições, quanto à qualidade destas para a manutenção de garantias democráticas.

\section{ESTABILIDADE E RUPTURA NA ANÁliSE DE POLÍTICAS PÚBLICAS: A TEORIA DO EQUILÍBRIO PONTUADO}

A discussão acerca da estabilidade e da mudança englobando o viés institucional também se estende aos estudos relativos às políticas públicas. Através do modelo proposto pelos autores Baumgartner e Jones, intitulado Teoria do Equilíbrio Pontuado, é possível perceber clara conexão com os pensadores do neoinstitucionalismo, além dos avanços em outros pontos que enriquecem a análise destacada de busca pela compreensão da estabilidade e da ruptura no fenômeno político e social.

O estudo de políticas públicas, inserido no campo da Ciência Política, consiste em uma tarefa árdua para aqueles que se propõem a realizá-lo. Isso porque se baseia em um processo que envolve uma série de atores, ideias, instituições, interesses e percepções, em períodos de tempo que podem ser extensos quando relacionados a certa ação governamental. Com isso, o trabalho de Lasswell (1956) contribui significativamente ao propor o ciclo de políticas públicas, concebido como o processo de definição de agenda, identificação de alternativas, avaliação das opções, seleção das opções, implementação e avaliação (Souza, 2007). Esta fragmentação do conteúdo das políticas em etapas simplificou a possibilidade de análises e, certamente, viabilizou o desenvolvimento do próprio campo (GELINSKY, SEIBEL, 2008). 
Os estudos baseados na ideia de etapas ou ciclos, como mencionado, predominaram até final da década de 70, caracterizando o "período clássico" de estudos sobre políticas públicas, com foco no processo decisório. No entanto, a partir de meados de 1980, há a proposição de novas formas de análises, destacando a influência de ideias, da linguagem e da argumentação (argumentative turn). Passam a surgir modelos sintéticos, ou teorias sintéticas, que articulam o conhecimento produzido pela pesquisa em instituições, redes, processos socioeconômicos, escolha racional e ideias. Constituise a análise de políticas públicas a partir dos vários aspectos de influência teórica, de um campo amplo e multidisciplinar (CAPELLA, SOUZA, BRASIL, 2014).

Destes modelos, três principais abordagens são destacadas pela capacidade de análise e oferta de respostas no campo das políticas públicas: a abordagem dos múltiplos fluxos, proposta por John Kingdon em 1984, o modelo das coalizões de defesa apresentado por Sabatier e Jenkins-Smith inicialmente em 1993 e o modelo de equilíbrio pontuado desenvolvido por Baumgartner e Jones em 1993. Segundo John (2013 apud CAPELLA, 2014) há poucos avanços teóricos posteriores a estes modelos, o que significa que estas três abordagens constituem hoje o "estado da arte" do campo.

O modelo do Equilíbrio Pontuado foi elaborado com base nas noções de biologia. Posteriormente ao modelo Darwinista, que afirma que o processo de diferenciação das espécies ocorre de forma lenta e gradual, há a divulgação das ideias de dois paleontólogos, Stephen Gould e Niles Eldredge, acerca da ideia de que mudanças acontecem de forma rápida em certos períodos, com a extinção de espécies e substituição destas por outras - punctuated equilibrium theory.

Baumgartner e Jones (1993), por sua vez, procuraram criar um mecanismo que permitisse explicar momentos de estabilidade e de mudanças drásticas no processo de formulação de políticas púbicas.

Ponctuated-equilibrium theory seeks to explain a simple observation: potical processes are often driven by a logic of stability and incrementalism, but occasionally they also produce large-scale departures from the past. (BAUMGARTNER E JONES, 1999, p.97).

O modelo é concebido a partir da ideia de que os processos políticos são marcados por longos períodos de estabilidade e que mudanças ocorrem sempre de forma incremental, ou seja, apenas de forma corretiva, como pequenos ajustes frente ao que já se possui. No entanto, há momentos em que esta estabilidade é quebrada por processos de rupturas e mudanças drásticas, que farão com que a política vigente mude e passe a operar com padrões diferentes. 
Desse modo, o objetivo do modelo é analisar e explicar tantos os momentos de estabilidade como os momentos de mudanças rápida, baseando-se em dois principais eixos: estruturas institucionais e processo de agenda-setting (CAPELLA, 2006).

Segundo os autores (Baumgartner e Jones, 1993), os indivíduos que integram o processo de política operam com racionalidade limitada e uma multiplicidade de questões. Isso faz com que os governos deleguem aos agentes governamentais, em subsistemas, o papel de processamento destas questões. Os subsistemas são compostos por grupos de atores (políticos, especialistas no assunto, lobistas, burocratas) que se focam em uma determinada questão referente a política pública. Os subsistemas sempre processam as questões de forma paralela enquanto os líderes governamentais (o macrossistema) se preocupa com as questões centrais naquele momento e as processam de forma serial (uma a uma).

Certas questões permanecem nos subsistemas e quando estas caracterizam um único interesse, há o surgimento do monopólio de políticas (policy monipoly). Duas características constituem um monopólio: estrutura física definida e uma ideia fortemente associada com a instituição e com os valores políticos da comunidade.

“os monopólios são responsáveis pela manutenção da estabilidade na produção de políticas públicas e restrição de novas questões à agenda governamental. Mudanças nas políticas ocorrem quando os monopólios se desestruturam" (CAPELLA, 2016, p.492).

Quando há o monopólio no subsistema há maior controle, pois atores e procedimentos institucionais geram mudanças incrementais associadas ao contexto legal, político, orçamentário. Essa hegemonia no tratamento das questões presentes e na definição da ideia no subsistema se caracteriza como feedback negativo. (CARVALHO, 2013).

Em oposição, quando incidirem na política ideias, valores e símbolos que questionem a concepção atual, surgirá a possibilidade para entrada de atores e novas ideias no subsistema. Essa situação alterará o monopólio da política, caracterizando o feedback positivo (CARVALHO, 2013). Ou seja, a forma como uma ideia é definida, bem como sua associação institucional, é o ponto principal para a compreensão dos períodos de mudança e estabilidade.

Para auxiliar na compreensão deste processo de construção da ideia os autores apresentaram o conceito de policy image. Esta representa como a ideia acerca de uma questão (issue) é compreendida e discutida. É a policy image que sustenta os arranjos institucionais e permite a melhor "defesa" da ideia na comunidade política. Consequentemente, viabiliza a entrada da ideia no macrossistema, caracterizando o momento da mudança na política. (CAPELLA, 2016). 
Dois componentes são essenciais para o desenvolvimento da policy image: as informações empíricas e os apelos emotivos (tone). Os autores do modelo acreditam que uma política pública ou questão social - não se torna prioridade e ascende para o macrossistema automaticamente. Para tanto, faz-se necessária a construção de uma imagem, conectando problemas e soluções. Destaca-se que os apelos emotivos podem influenciar fortemente a mobilização em torno de uma ideia. É essencial a policy image na luta política, assim como o processo para a construção de consenso acerca da mesma.

Com isso, o modelo indica que as grandes mudanças na política advêm das alterações nas preferências e na atenção dedicada, o que por sua vez influencia a imagem da política consolidada anteriormente. Imagens bem estabelecidas quando contestadas permitem a entrada de novos atores e ideias o que potencializa a subida da questão do microssistema para o macrossistema (TRUE; JONES; BAUNGARTNER, 2007).

No entanto, apenas a percepção de um problema pela comunidade não garante necessariamente que haja uma solução definida. Para que esse processo, de encontro entre problemas e solução ocorra, Baumgartner e Jones (1993) apresentam a figura do empreendedor político (policy entrepreneur). Kingdon (2003) também evidencia a importância do policy entrepreneur em seu modelo (multiple stream model) e o define como indivíduos (eventualmente pequenos grupos de pessoas) que defendem uma ideia e percebem os momentos exatos para conectar problemas e soluções (janelas de oportunidades), viabilizando a mudança em políticas públicas. Logo, depreendese que a policy image é essencial não apenas para a definição dos problemas, mas também para a seleção das soluções.

Importante destacar que a policy image deve ser considerada sempre associada ao contexto institucional em que é desenvolvida. Isso porque as decisões são tomadas pelas instituições em locais denominados policy venue: "Policy venues are the institucional locations where authoritative decisions are made concerning to a given issue” (BAUNGARTNER E JONES, 1993, p.32).

Se, por um lado, a imagem da política sustenta a arquitetura institucional, por outro, esta mesma imagem é criada dentro de espaços institucionais (policy venue), o que nos permite aprofundar essa relação. Na luta pela definição da imagem, principalmente em contextos que apresentam monopólios - forte coesão em torno de uma ideia predominantes - os atores e empreendedores com diferentes propostas, buscarão espaços que priorizem suas ideias. Ou seja, deste embate é possível surgir diferentes espaços institucionais com diferentes imagens de uma mesma questão pública, 
gerando uma disputa institucional. "Cada espaço institucional pode ser o lar para uma diferente imagem da mesma questão", lutando pela atenção governamental (BARCELOS, 2016, p. 73).

Enfim, o modelo do Equilíbrio Pontuado nos fornece explicações acerca dos momentos de mudanças lentas, incrementais, de equilíbrio, resultado da configuração de um monopólio e feedback negativo. Igualmente, fornece-nos explicações acerca das mudanças radicais, de pontuação, resultado de questões que migram do subsistema para o macrossistema político, feedback positivo.

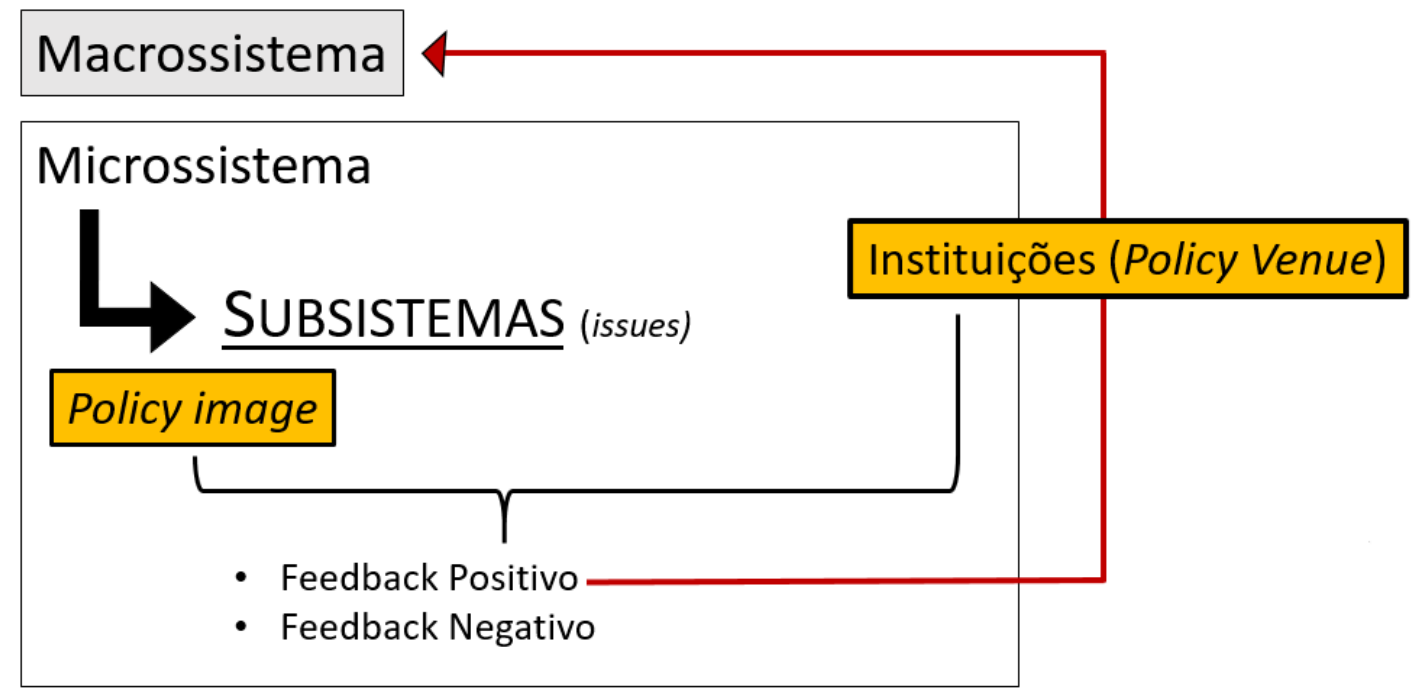

Fonte: elaborada pelo autor.

Figura 1: Estrutura teórica para explicar o Modelo do Equilíbrio Pontuado.

\section{CONSIDERAÇÕES FINAIS}

Dada as informações presentes neste trabalho, é possível perceber a importância da relação teórica neoinstitucional com o campo de análise de políticas públicas mais recente, principalmente no que diz respeito ao debate acerca da estabilidade, continuidade versus mudanças, rupturas da ordem estabelecida.

Quando aproximamos esta discussão do tema democracia, torna-se ainda mais perceptível o quanto é caro para a Ciência Política compreender os processos políticos que, obviamente, favorecerem a manutenção do regime democrático - aqui destacando as instituições como importantes redutores de incerteza - e, ainda mais, compreender com maior profundidade os momentos de ruptura, do novo, de incerteza que, apesar de menos frequentes, são partes do processo que, na maioria das vezes, ocorrem associados a momentos de crises e instabilidades. 
A Teoria do Equilíbrio Pontuado claramente dialoga com as discussões da estabilidade e rupturas das instituições apresentadas previamente e contribui ao apresentar uma forma organizada de entender a mudança de agenda do governo através de processos articulados por empreendedores políticos. A proposição da imagem política (policy image) que sintetiza ideias, redes, atores, instituições em torno de novas demandas ricamente se relaciona com as ideias defendidas por Levi (1991) acerca do desajuste na distribuição de poder e a construção de consensos que acomodem esses novos grupos em novas concepções de solução para os problemas. É bastante próxima a relação que se pode estabelecer entre monopólios de política e distribuição de poder.

Destaca-se também, a partir do exercício teórico e analítico realizado, a importância do olhar para os atores, empreendedores de políticas pública, no processo de alterações institucionais e de políticas públicas. Nesse sentido, os trabalhos de Mahoney e Thelen (2010) com as análises de contextos políticos e dos agentes impulsionadores do processo de mudança se aproximam da dinâmica de construção de policy images defendidas por Baungartner e Jones (1993). A entrada do processo de argumentação, disputa de interesses, barganhas e jogos de poder passam a ocupar lugar de destaque nas teorias historicamente associadas a centralidade das instituições. Os atores são encarados não apenas como receptores, passivos e constrangidos do processo, mas sim, como atores ativos e agentes do processo.

Por fim, de acordo com estudo produzido por Capella, Soares e Brasil (2014), no qual foi realizado o mapeamento da aplicação de modelos internacionais recentes de análise de políticas públicas na literatura nacional, constatou-se que no período de 2003 a 2013 apenas dezessete estudos nacionais aplicaram o modelo do equilíbrio pontuado como instrumento metodológico para a condução de teses e dissertações. Foram identificados onze tipos de políticas setoriais diferentes, das quais prevaleceram estudos nas áreas de Segurança, Regulação, Transporte, Saúde e Assistência Social.

Apesar de ainda pouco conhecidos e necessitarem de mais aplicações e análises voltadas especificamente para a realidade brasileira (CAPELLA, SOARES, BRASIL, 2014), modelos como o proposto por Baungartner e Jones ocupam lugar de destaque no debate neoinstitucional ao oferecer um instrumental de análise de políticas públicas que permite melhor compreender a mudança institucional, debate ainda carente de informações na literatura sobre o tema. 


\section{REFERÊNCIAS}

BARCELOS, MÁRCIO. (2015). "Ideias, agendas e políticas públicas: um estudo sobre a área de biocombustíveis no Brasil”. Tese de Doutorado apresentada ao Programa de Pós-graduação em Sociologia da Universidade Federal do Rio Grande do Sul. Porto Alegre, UFRGS. (239 p.)

BAUMGARTNER, Frank R; JONES, Bryan D. (1993) Agendas and Instability in American Politics. Chicago, University of Chicago Press.

CAPELLA, Ana C. N. (2004). “O processo de Agenda-Setting na Reforma da Administração Pública (1995-2002)". Tese de Doutorado apresentada ao Programa de Pós- Graduação em Ciências Sociais (PPGCSo) da Universidade Federal de São Carlos. São Carlos, UFSCar. (234 p.).

(2006). "Perspectivas Teóricas sobre o Processo de Formulação de Políticas Públicas”. BIB - Revista Brasileira de Informação Bibliográfica em Ciências Sociais. São Paulo, ANPOCS (pp. 25-52).

(2016). Um estudo sobre o conceito de empreendedor de políticas públicas: Ideias, Interesses e Mudanças. Cad. EBRAPE.BR, v. 14, Edição Especial, Artigo 5, Rio de Janeiro, Jul. 2016.

CAPELlA, Ana C. N; SOARES, Alessandra G.; e BRASIL, Felipe G. "Pesquisa em Políticas Públicas no Brasil: Um mapeamento da aplicação de modelos internacionais recentes na literatura nacional". In IX Encontro da ABCP. Anais eletrônicos. Associação Brasileira de Ciência Política, 2014. Disponível em < http://www.encontroabcp2014.cienciapolitica.org.br/resources/anais/14/1403738847_ARQUIVO_ ABCP_final.pdf. Acesso em 20 out. 2014.

CARVALHO, C. M. Esporte como Política Pública: um estudo sobre o processo de formulação da política de esporte no Brasil. Dissertação (Mestrado em Ciência Política) - Universidade Federal de São Carlos -UFSCar, São Paulo, 2013.

DAHL, Robert. (1963). Modern political analysis. New Jersey, Englewood Cliffs.

DIMAGGIO, P. J. Interest and Agency in Institutional Theory. In L. G. ZUCKER (Ed.), Institutional Patterns and Organizations: Culture and Environment: pp. 3-20. Cambridge, MA: Ballinger, 1988.

GELINSKI, Carmen Rosário Ortiz G., SEIBEL, Erni José. Formulação de políticas públicas: questões metodológicas relevantes. Revista de Ciências Humanas, Florianópolis, EDUFSC, $\mathrm{n}^{\circ} 1$ e 2, v. 42, p. 227-240. Abr/ Out de 2008.

GOMES, L. O. M. Processos de mudança institucional: estudo de caso de cinco ouvidorias de agências reguladoras federais. Tese de doutorado - Universidade de Brasília / Unb. Brasília, 2013.

HALL, P.; TAYLOR, R. As três versões do neoinstitucionalismo. Lua Nova, São Paulo, n. 58, p. 193-224, 2003.

KINGDON, John. Agendas, Alternatives and Public Policies. 3a. Ed. New York: Harper Collins, [1984] 2003. 
LASSWELL, Harold D. (1956). The Decision Process: Seven Categories of Functional Analysis. College Park: University of Maryland Press.

LEVI, Margaret. Uma lógica da mudança institucional. DADOS. Revista de Ciências Sociais, Rio de Janeiro, Vol. 34, n. 1, 1991, pp. 79 a 99.

MAHONEY, J. \& THELEN, K. A Theory of Gradual Institutional Change. IN: MAHONEY, J. \& THELEN, K (Eds): Explaining Institutional Change - Ambiguity, Agency and Power. New York: Cambridge University Press, 2010, pp. 1-37.

MARQUES, Eduardo C.. Notas críticas à literatura sobre Estado, Políticas Estatais e atores políticos. BIB, Rio de Janeiro, n. 43, 1. ${ }^{\circ}$ semestre de 1997, pp. 67-102

MOISÉS, J. A.. A desconfiança nas instituições democráticas. Opinião Pública, Campinas, Vol. XI, março, 2005, p. 33-63.

NORTH, D. Institutional Change: a framework of analysis. In: SJÖSTRAND, S. E. Institutional Change. Armonk: Studies in Socio-Economics, 1993. p.35-46.

PERES, Paulo Sérgio. Comportamento ou instituições? A evolução histórica do neoinstitucionalismo da ciência política. Revista Brasileira de Ciências Sociais. Vol. 23, nº 68, out., 2008.

PRZEWORSKI, A.; CHEIBUB. J. A.; LIMONGI, F. Democracia e cultura: uma visão não culturalista. Lua Nova: Revista de Cultura e Política, n. 58, p. 9-35, 2003.Rocha, 2009.

ROTHSTEIN, B. Political Institutions: an Overview. In: GOODIN, R. E.; KLINGEMANN, H. D. (Ed.). A New Handbook of Political Science. New York: Oxford University Press, 1998. p.133-166.

SABATIER, P. A.; JENKINS-SMITH, H. C. Policy Change and Learning: Na Advocacy Coalition Approach. Oxford: Westview Press, 1993.

SOUZA, Celina. Estado da arte da pesquisa em Políticas públicas. In: HOCHMAN, G; ARRETCHE, M. \& MARQUES, E. Políticas públicas no Brasil. Rio de Janeiro: Editora FIOCRUZ, 2007.

ROCHA, Carlos V..Democracia em duas dimensões: cultura e instituições. Sociedade e Estado, Brasília, v. 24, n.3, p. 863 - 880, set./dez., 2009,

TRUE, James L.; JONES, Bryan D; BAUNGARTNER, Frank R. Punctuated Equilibrium Theory: explaining stability and change in public policymaking. In: SABATIER, Paul A. (Ed.) Theories of the policy process. 2. ed. Boulder: Westview Press, 2007. P. $155-187$ 